\title{
Biomarkers of the Physical Function Mobility Domains Among Patients Hospitalized in Internal Medicine
}

\author{
Petra VRBOVÁ ${ }^{1}$, Simona VALÁŠKOVÁ ${ }^{2}$, Andrea GAŽOVÁ ${ }^{3}$, Juraj SMAHA ${ }^{1}$, Martin \\ KUŽMA ${ }^{1}$, Ján KYSELOVIČ ${ }^{1}$, Juraj PAYER ${ }^{1}$, Tomáš KOLLER ${ }^{1}$
}

${ }^{1} 5^{\text {th }}$ Department of Internal Medicine, Comenius University Faculty of Medicine, University

Hospital Bratislava, Slovakia, ${ }^{2}$ Department of Pharmacology and Toxicology, Comenius University Faculty of Pharmacy, Bratislava, Slovakia, ${ }^{3}$ Institute of Pharmacology and Clinical Pharmacology, Comenius University Faculty of Medicine, Bratislava, Slovakia

Received March 28, 2021

Accepted August 13, 2021

\section{Summary}

Hospitalized patients in internal medicine have an increased risk of low physical reserve which further declines during the hospital stay. The diagnosis requires bed-side testing of functional domains or more complex investigations of the muscle mass. Clinically useful biomarkers of functional status are needed, thus we aimed to explore the potential of microRNAs. Among hospitalized patients, we recorded the basic demographics, anthropometrics, nutritional status, and physical function domains: hand-grip strength (HGS, abnormal values $\mathrm{M}<30 \mathrm{~kg}$, $\mathrm{W}<20 \mathrm{~kg}$ ), balance $(<30 \mathrm{~s})$, chair-stands speed (CHSS $<0.5 / \mathrm{s})$ and gait speed (GS<0.8 m/s). A panel of five micro-RNAs (miRNA 1, miRNA 133a, miRNA 133b, miRNA 29a, miRNA 29b) and basic blood biochemistry and vitamin $D$ values were recorded. We enrolled 80 patients (M40, W40), with a mean age of $68.8 \pm$ 8.4 years. Obesity was observed in $27.5 \%$ and $30 \%$, low HGS and low CHSS in 65.0, 77.5\%, and 80, $90 \%$ of men and women respectively. The median hospital stay was 6.5 days. MiRNA29a and miRNA29b have the strongest correlation with the triceps skinfold (miRNA 29b, $r=0.377, p=0.0006$ ) and CHSS (miRNA 29a, $r=0.262, p=0.02$ ). MiRNA 29a, miRNA 29b and 133a levels were significantly higher in patients with $\mathrm{CHSS}<0.5 / \mathrm{s}$. Other anthropometric parameters, mobility domains, or vitamin $D$ did not correlate. All miRNAs except of miRNA 1, could predict low CHSS (miRNA29b, AUROC $=0.736$ CI $0.56-0.91, p=0.01$ ), particularly in patients with low HGS (miRNA 29b, AUROC $=0.928$ CI 0.83-0.98). Among hospitalized patients in internal medicine, low functional status was frequent. MicroRNAs were fair biomarkers of the antigravity domain, but not other domains. Larger studies with clinical endpoints are needed.

\author{
Key words \\ microRNA - Frailty - Sarcopenia - Biomarker - Mobility • \\ Hospitalization • Internal medicine
}

\section{Corresponding author}

Petra Vrbová, $5^{\text {th }}$ Department of Internal Medicine, Comenius University Faculty of Medicine, University Hospital Bratislava, Ruzinovska 6, 82606 Slovak Republic. E-mail: petra5.vrbova@googlemail.com

\section{Introduction}

Frailty and sarcopenia are common age-related conditions observed mainly in the elderly, but also among younger patients with chronic diseases (Oliveira et al. 2020). Both are associated with a higher risk of adverse consequences such as falls, fractures, mobility disorders, re-hospitalizations, low quality of life, and death (Skladaný et al. 2018, Vrbová et al. 2019, Gingrich et al. 2019). The prevalence is reaching $50 \%$ among hospitalized patients with an increasing trend in higher age groups (Gingrich et al. 2019). Caring for these patients represents a significant burden in terms of consuming health care and social service resources (Papadopoulou 2020, World Health Organization 2017). The European Working Group on Sarcopenia in Elderly People (EWGSOP) has defined sarcopenia as a progressive and generalized muscle disease characterized by a progressive and generalized loss of muscle mass, muscle strength, or muscle function (CruzJentoft et al. 2019). In contrast, frailty is characterized by

PHYSIOLOGICAL RESEARCH • ISSN 1802-9973 (online) - an open access article under the CC BY-NC-ND 4.0 license (c) 2021 Institute of Physiology of the Czech Academy of Sciences, Prague, Czech Republic Fax +420 241062 164, e-mail: physres@fgu.cas.cz, www.biomed.cas.cz/physiolres 
vulnerability to acute environmental stressors resulting from reduced functional reserve associated with physiological aging of organ systems (Chen et al. 2014). In recent years, the definition of sarcopenia has shifted more towards the assessment of muscle function and functional status, bringing the definitions of frailty and sarcopenia much closer together (Picca et al. 2020). The prevalence of physical frailty is estimated at around $15 \%$ in people over 65 (O'Caoimh et al. 2018), reaching over $25 \%$ over the age of 85 (Collard et al. 2012). Frail patients have a 3.5 -fold risk of mortality with a longer hospital stay and a higher risk of functional decline at discharge compared to non-frail (Cunha et al. 2019). As research to date has shown, there is great potential for reversing frailty, especially in its early stages. For this reason, early identification of low functional status in hospitalized patients should be an important priority in the field of medicine (Dent et al. 2019). The diagnosis is currently based on clinical, functional, and imaging parameters (Chen et al. 2014, Cruz-Jentoft et al. 2019). Although a relatively large number of metabolic, microbial, and inflammatory biomolecules have already been studied, a clear biomarker that can easily and reliably predict functional impairment is lacking (Picca et al. 2020).

Micro RNAs (miRNAs) are short non-coding RNAs that regulate gene expression and were shown to modulate myogenesis, tissue regeneration, and cell programming in skeletal muscles (Brown and GoljanekWhysall 2015, Dlouhá and Hubáček 2017). Once released from the cell, they are detectable in most body fluids including serum and plasma. Muscle-specific miRNAs expressed exclusively by the muscle are called MyomiRNAs (myomiRs) (Goljanek-Whysall et al. 2016). It has been found that miRNAs are identified in the circulation of healthy individuals, individuals with muscle disease, with different expressions during aging (Nie et al. 2015). Circulating miRNAs emerge as promising biomarkers for assessing skeletal muscle mass and function (Brown and Goljanek-Whysall 2015, Goljanek-Whysall et al. 2016, Gažová et al. 2019). Therefore, we aimed to explore the selected musclespecific miRNAs: miRNA 1, miRNA 29a, miRNA 29b, miRNA 133a, miRNA $133 \mathrm{~b}$ as potential biomarkers to the selected objective functional mobility domains in hospitalized patients in internal medicine.

\section{Methods}

Our study group consisted of consecutive patients hospitalized at the 5th department of Internal Medicine from June 2019 until February 2020. Inclusion criteria were hospitalization, age above 55 years, ability to stand-up from a chair, and ability to cooperate in measuring the hand-grip strength. We excluded patients who were bed-bound on admission, patients with terminal stage of disease, those with active malignant disease and/or hospitalized at the intensive care unit. In all patients, we assessed the following anthropometric parameters: body mass index (BMI, $\left.\mathrm{kg} / \mathrm{m}^{2}\right)$, mid-arm circumference $(\mathrm{cm})$, tricipital skinfold $(\mathrm{cm})$, and subscapular skinfold. Skinfolds were measured using a caliper method (personal body fat tester). We measured the following functional domains: handgrip strength (HGS), chairs stand speed (CHSS), gait speed (GS) and balance test (BT). HGS was assessed using a hand-grip dynamometer (Gima S.p.A. Via Marconi, 1, 20060 Gessate, Italy) by calculating an average value from 3 measurements. Normal handgrip strength values were derived from previous reports (women $<20 \mathrm{~kg}$, men $<30$ $\mathrm{kg}$ ). CHSS test was used to determine the time (T), needed for five chairs stands without the help of hands. The speed was calculated with the formula $(\mathrm{CHSS}=5 / \mathrm{T})$ and abnormal values were defined as less than $0.5 / \mathrm{s}$. BT was used to determine the time $(\mathrm{T})$, needed for maintain balance having feet together, at the semi tandem, and tandem position, for a maximum of 10 seconds by adding-up the three times. Abnormal BT was defined as less than 30s. GS test was used to measure the time $(\mathrm{T})$, needed to walk five meters. The GS was calculated with the formula $(\mathrm{GS}=5 / \mathrm{T})$ and abnormal values are defined as less than $0.8 \mathrm{~m} / \mathrm{s}$.

Fat-free mass and fat mass were assessed using an electrical bioimpedance device ImpediMed IMP SF7 (ImpediMed Inc. 5900 Pasteur Court, Suite 125, Carlsbad, CA, USA). The measurement was carried out in a supine position, all the electrodes were placed unilaterally on a non-dominant upper limb (yellow electrode - next to the ulna head, a red electrode at the center of the dorsal arm at a distance of $2-5 \mathrm{~cm}$ from the yellow electrode) and lower limb (blue electrode - center between the medial and lateral malleoli, black electrode the center of the foot dorsum at a distance of $2-5 \mathrm{~cm}$ from the blue electrode). From the measured parameters, we assessed the fat-free mass and the fat mass in $\mathrm{kg}$, which was converted into the fat-free mass index (FFMI) and fat mass index (FMI) divided by the square of body height.

From the laboratory parameters, we have sampled basic hematology (full blood count) and biochemistry (serum creatinine, bilirubin, urea, $\mathrm{C}$ reactive 
protein and vitamin D). Venous blood samples were drawn in the morning at a fasting state into siliconecoated serum tubes with enhanced silica-containing clot activator. At $4{ }^{\circ} \mathrm{C}$, blood samples were centrifuged at 3,500 rpm. Within 10 minutes the plasma was immediately aliquoted and frozen at $-80^{\circ} \mathrm{C}$ until further analyses.

Table 1. Summary statistics and characteristics of the study group

\begin{tabular}{|c|c|c|c|}
\hline & $\begin{array}{c}\text { Men, } n=40 \\
\text { Median [25-75], n (\%) }\end{array}$ & $\begin{array}{c}\text { Women, } n=40 \\
\text { Median }[25-75], \mathrm{n}(\%)\end{array}$ & P value \\
\hline Age, years & $68.50[60.00,73.00]$ & $70.00[65.00,76.25]$ & 0.111 \\
\hline Body mass index, $\mathrm{kg} / \mathrm{m}^{2}$ & $27.38[25.41,31.11]$ & $27.49[25.38,31.96]$ & 0.855 \\
\hline Waist circumference, $\mathrm{cm}$ & $107.50[100.75,115.75]$ & $104.50[94.00,118.00]$ & 0.386 \\
\hline \multicolumn{4}{|l|}{ BMI categories, $n(\%)$} \\
\hline normal & $7(17.5)$ & $7(17.5)$ & 1.000 \\
\hline overweight & $21(52.5)$ & $20(50.0)$ & \\
\hline obese & $11(27.5)$ & $12(30.0)$ & \\
\hline underweight & $1(2.5)$ & $1(2.5)$ & \\
\hline Mid-arm circumference, $\mathrm{cm}$ & $29.50[27.00,31.00]$ & $30.00[27.50,33.00]$ & 0.524 \\
\hline Skinfold scapula, $\mathrm{cm}$ & $2.00[1.48,2.20]$ & $2.20[1.98,2.62]$ & 0.005 \\
\hline Skinfold triceps, $\mathrm{cm}$ & $1.20[0.97,1.80]$ & $2.35[1.87,2.82]$ & $<0.001$ \\
\hline Balance, $s$ & $30.00[22.00,30.00]$ & $28.00[20.00,30.00]$ & 0.527 \\
\hline Balance $<30 s$ & $19(47.5)$ & $21(52.5)$ & 0.823 \\
\hline Gait speed, $m / s$ & $0.71[0.44,1.00]$ & $0.68[0.50,0.97]$ & 0.813 \\
\hline Gait speed, $<0.8 \mathrm{~m} / \mathrm{s}$ & $22(55.0)$ & $24(60.0)$ & 0.821 \\
\hline Handgrip strength, $\mathrm{kg}$ & $25.50[18.96,32.38]$ & $16.08[14.08,19.29]$ & $<0.001$ \\
\hline $\begin{array}{l}\text { Handgrip strength }(F<20, M<30), n \\
(\%)\end{array}$ & $26(65.0)$ & $31(77.5)$ & 0.323 \\
\hline Chair-stands (/s) & $0.34[0.25,0.45]$ & $0.36[0.31,0.42]$ & 0.736 \\
\hline Chair-stands <0.5/s, n (\%) & $32(80.0)$ & $36(90.0)$ & 0.348 \\
\hline Fat-free mass index & $20.74[19.30,22.50]$ & $18.21[16.54,20.89]$ & 0.007 \\
\hline Fat-mass index & $7.13[4.44,9.60]$ & $8.60[6.88,11.32]$ & 0.040 \\
\hline Hemoglobin, $g / l$ & $122.50[105.75,134.25]$ & $122.00[109.25,128.25]$ & 0.851 \\
\hline Serum bilirubin, umol/l & $15.11[9.45,26.59]$ & $9.90[5.90,12.99]$ & 0.012 \\
\hline Serum creatinine & $88.7[78.3,122.9]$ & $76.4[66,92.2]$ & 0.009 \\
\hline Serum urea, mmol/l & $5.95[4.81,8.59]$ & $4.88[3.12,8.71]$ & 0.040 \\
\hline C-reactive protein & $18.04[2.0,55.4]$ & $5.4[2,23.01]$ & 0.26 \\
\hline Vitamin D & $16.5[11.3,22]$ & $15.3[12.1,21.97]$ & 0.851 \\
\hline \multicolumn{4}{|l|}{ Micro RNAs (Ct) } \\
\hline miRNA1 & $33.50[31.75,35.82]$ & $34.20[31.53,36.13]$ & 0.533 \\
\hline $\operatorname{miRNA133a}$ & $31.62[30.54,34.31]$ & $32.90[31.30,35.98]$ & 0.122 \\
\hline $\operatorname{miRNA133b}$ & $32.20[30.93,35.25]$ & $33.25[31.40,36.60]$ & 0.148 \\
\hline $\operatorname{mirRNA29a}$ & $26.98[25.87,28.84]$ & $29.29[26.34,32.10]$ & 0.029 \\
\hline $\operatorname{mir} R N A 29 b$ & $29.17[28.45,31.67]$ & $32.79[28.90,35.21]$ & 0.019 \\
\hline Days in the hospital & $7[5,10]$ & $6[4,8]$ & 0.238 \\
\hline
\end{tabular}

\section{MiRNA analysis}

RNA Isolation: The plasma was dissolved at room temperature. For stability, repeated freezing and thawing cycles of serum samples were minimized. Isolation was performed on the miRNeasy Serum/Plasma
Advanced Kit. Control ce-miRNA-39 (miRNeasy serum/plasma Spike-In control) was added to the process. The process resulted in total RNA eluate from $200 \mu \mathrm{l}$ of the patient's plasma. Reverse RNA Transcription: Commercially available miRCURY LNA RT Kit 
(Qiagen) was used for reverse transcription according to the manufacturer's instructions. The resulting cDNA was further analyzed by qPCR. QPCR method: The target sequence was analyzed by qPCR miRCURY LNA SYBR ${ }^{\circledR}$ Green PCR Kits (Qiagen, GmbH, Germany). The PCR reaction was performed in a StepOnePlus RealTime PCR System (Life Technologies, USA). The lists the PCR primers used in this study:

\begin{tabular}{llll}
\hline microRNA & $\begin{array}{l}\text { LNA PCR } \\
\text { primer ID }\end{array}$ & microRNA & $\begin{array}{l}\text { LNA PCR } \\
\text { primer ID }\end{array}$ \\
\hline cel-miR-39-3p & YP00203952 & hsa-miR-133a-3p & YP00204788 \\
hsa-miR-1-3p & YP00204344 & hsa-miR-133b & YP00206058 \\
hsa-miR-29a-3p & YP00204698 & hss-miR-29b-3p & YP00204679 \\
\hline
\end{tabular}

The study has been following the proceedings of the Declaration of Helsinki and further amendments. The study protocol and the informed consent form have been approved by the ethics committee of the University Hospital in Bratislava. Study participants signed informed consent before any procedure and agreed with anonymized storage and publication of data.

Numerical data had predominantly a non-normal distribution thus the results are provided as medians and 25 to 75 percentiles. Proportions are given as numbers and percentages. Associations between numerical parameters were explored with Spearman rank correlation providing the coefficient (rho), p-value and the scatter plot with regression line. For comparison of numerical parameters or proportions between groups, we used Mann-Whitney or chi-square test respectively. For exploring the diagnostic value of miRNA levels in the prediction of abnormal functional domains we used the area under the receiver operating curve according to DeLong et al. giving the AUROC value, $95 \%$ confidence interval, p-value, cut-off of miRNA, sensitivity, and specificity of the test. Missing values were treated as missing and were not accounted. The Statistical analysis was carried out using the MedCalc software (MedCalc bvb, Ostende, Belgium).

\section{Results}

We enrolled 80 patients (40 women, 40 men) with the median age of 70.0 and 68.5 years respectively. The great majority of patients were overweight (>50\%) or obese $(>27.5 \%)$. Summary statistics and characteristics of the study group are displayed in Table 1. Patients mostly suffered from cardiovascular disease (36.2\%), liver and gastrointestinal disease (25\%), sepsis $(13.8 \%)$, metabolic disease (11.2\%), blood dyscrasias $(8.8 \%)$, and chronic renal disease $(5 \%)$. From the anthropometric measurement, women had significantly thicker scapular and tricipital skinfold compared to men. From the physical function domain parameters in men and women respectively, low HGS was observed in 65 and $77.5 \%$, low CHSS in 80 and $90 \%$, low gait speed in 55 and $60 \%$ and low balance time in 47.5 and $52.2 \%$ of patients. Women had lower HGS, lower fat-free mass index and higher fat-mass index compared to men. From the laboratory parameters, women had lower serum urea, creatinine and bilirubin. From the miRNAs, women had lower miRNA 29a and $29 \mathrm{~b}$, and the difference in other miRNAs between the genders was not statistically significant.

By exploring the association between miRNA levels and four numerical functional parameters, we found a low but significant correlation between miRNA $29 \mathrm{a}$ and $29 \mathrm{~b}$ and chair stand speed $(\mathrm{r}=0.262, \mathrm{r}=0.257)$. We also found a significant correlation between tricipital skinfold and both miRNAs 133a, miRNA 133b, miRNA $29 \mathrm{a}$ and miRNA $29 \mathrm{~b} \quad(\mathrm{r}=0.264,0.31,0.36,0.38$ respectively). Other functional domain parameters (HGS, GS, BT) or body composition indices (BMI, fat mass index, fat-free mass index) did not correlate with miRNAs (Table 2). Likewise, by comparing miRNA levels according to functional domain categories, we observed that patients with low CHSS $(<0.5 / \mathrm{s})$ had significantly higher miRNA 29a, miRNA 29b and miRNA 133a than patients with normal CHSS. Among other functional domain categories, we did not find any difference in miRNA levels (Table 3, Fig. 1).

Besides, we compared the association between miRNA29 and CHSS separately for patients with suspected sarcopenia (low HGS) and those with normal HGS. We found that in patients with low hand-grip strength $(n=57)$ the correlation between miRNA 29a, miRNA 29b and CHSS was stronger (miRNA 29a, $\mathrm{r}=0.437$, miRNA 29b, $\mathrm{r}=0.392$ ). In contrast, among patients with normal HGS $(n=23)$, the correlation between CHSS and miRNA29a and miRNA 29b was completely lost ( $r=0,061$ or $r=0.067$, Fig. 2 ). Finally, we explored all miRNAs in the prediction of low CHSS. Results of the AUROC analysis are displayed in Table 4. It shows that miRNA 29a, miRNA 29b, and miRNA 133a could significantly predict abnormal CHSS and the predictive values had substantially improved in the subgroup of patients with low HGS compared with the entire study cohort. 
Table 2. Correlation table of the relevant parameters and miRNA levels in 80 patients

\begin{tabular}{|c|c|c|c|c|c|c|}
\hline $\mathrm{n}=\mathbf{8 0}$ & & miRNA1 & miRNA133a & miRNA133b & miRNA29a & miRNA29b \\
\hline \multirow[t]{2}{*}{ Age } & rho & -0.062 & -0.028 & -0.093 & -0.043 & -0.015 \\
\hline & $P$ value & 0.6121 & 0.8156 & 0.4323 & 0.7047 & 0.8963 \\
\hline \multirow[t]{2}{*}{$B M I, \mathrm{~kg} / \mathrm{m}^{2}$} & rho & 0.162 & 0.135 & 0.101 & 0.122 & 0.100 \\
\hline & $P$ value & 0.1831 & 0.2560 & 0.3901 & 0.2813 & 0.3811 \\
\hline \multirow[t]{2}{*}{ Waist circumf., cm } & rho & 0.140 & 0.019 & 0.018 & 0.058 & 0.044 \\
\hline & $P$ value & 0.2525 & 0.8722 & 0.8786 & 0.6097 & 0.7024 \\
\hline \multirow{2}{*}{ Hand-grip strength, $\mathrm{kg}$} & rho & -0.030 & -0.007 & -0.018 & 0.008 & -0.037 \\
\hline & $P$ value & 0.8044 & 0.9532 & 0.8795 & 0.9413 & 0.7483 \\
\hline \multirow[t]{2}{*}{ Midarm circumf., $\mathrm{cm}$} & rho & 0.099 & 0.121 & 0.119 & 0.143 & 0.112 \\
\hline & $\mathrm{P}$ value & 0.4183 & 0.3068 & 0.3130 & 0.2049 & 0.3269 \\
\hline \multirow[t]{2}{*}{ Triceps skinfold, $\mathrm{mm}$} & rho & 0.194 & 0.264 & 0.310 & 0.360 & 0.377 \\
\hline & $\mathrm{P}$ value & 0.1109 & 0.0242 & 0.0072 & 0.0011 & 0.0006 \\
\hline \multirow[t]{2}{*}{ Balance, $s$} & rho & -0.082 & 0.113 & 0.008 & -0.034 & -0.055 \\
\hline & $\mathrm{P}$ value & 0.5037 & 0.3415 & 0.9469 & 0.7638 & 0.6282 \\
\hline \multirow[t]{2}{*}{ Chair-stands/s } & rho & 0.098 & 0.213 & 0.214 & 0.262 & 0.257 \\
\hline & $\mathrm{P}$ value & 0.4216 & 0.0706 & 0.0671 & 0.0190 & 0.0221 \\
\hline \multirow[t]{2}{*}{ Gait speed, $\mathrm{m} / \mathrm{s}$} & rho & -0.073 & 0.037 & 0.030 & -0.005 & -0.021 \\
\hline & $\mathrm{P}$ value & 0.5538 & 0.7590 & 0.7997 & 0.9673 & 0.8566 \\
\hline \multirow[t]{2}{*}{ Hemoglobin, $g / l$} & rho & 0.039 & 0.022 & 0.038 & -0.137 & -0.103 \\
\hline & $\mathrm{P}$ value & 0.7489 & 0.8511 & 0.7466 & 0.2268 & 0.3673 \\
\hline \multirow[t]{2}{*}{ Serum creatinine } & rho & 0.021 & -0.044 & -0.073 & -0.001 & -0.009 \\
\hline & $\mathrm{P}$ value & 0.8648 & 0.7122 & 0.5368 & 0.9945 & 0.9401 \\
\hline \multirow[t]{2}{*}{ Serum urea, mmol/l } & rho & 0.072 & -0.068 & -0.048 & 0.008 & -0.002 \\
\hline & $P$ value & 0.5544 & 0.5663 & 0.6858 & 0.9427 & 0.9877 \\
\hline \multirow[t]{2}{*}{ Serum bilirubin, umol/l } & rho & -0.119 & -0.112 & -0.100 & -0.122 & -0.196 \\
\hline & $\mathrm{P}$ value & 0.3298 & 0.3446 & 0.3966 & 0.2794 & 0.0839 \\
\hline \multirow[t]{2}{*}{$C$-reactive protein } & rho & -0.068 & -0.032 & -0.120 & -0.077 & -0.064 \\
\hline & $\mathrm{P}$ value & 0.6018 & 0.7949 & 0.3325 & 0.5171 & 0.5928 \\
\hline \multirow[t]{2}{*}{ Vitamin D } & rho & -0.119 & -0.097 & -0.135 & -0.120 & -0.070 \\
\hline & $\mathrm{P}$ value & 0.3344 & 0.4198 & 0.2537 & 0.2912 & 0.5447 \\
\hline \multirow{2}{*}{ Fat mass index } & rho & 0.124 & 0.101 & 0.110 & 0.163 & 0.188 \\
\hline & $\mathrm{P}$ value & 0.3097 & 0.3954 & 0.3522 & 0.1497 & 0.0973 \\
\hline \multirow[t]{2}{*}{ Fat-free mass index } & rho & 0.015 & -0.021 & -0.038 & -0.022 & -0.108 \\
\hline & $\mathrm{P}$ value & 0.9016 & 0.8600 & 0.7506 & 0.8497 & 0.3419 \\
\hline
\end{tabular}

Spearman rank correlation coefficient

\section{Discussion}

In our study, we explored the association of selected miRNAs with functional mobility domains in hospitalized elderly patients. From all the functional domains, the only chair stands speed correlated with the selected miRNAs. The observed correlation was significant but relatively weak. However, miRNA29 and 133a could predict low chair stand speed with fair accuracy. Besides, in patients with low hand-grip strength, who are classified according to the EWGSOP2 consensus as those with suspected sarcopenia, the association was much stronger. Micro RNA29 and 133 could thus have potential as biomarkers for identifying patients with some aspects of impaired functional status, in this case, an impaired antigravitational domain. We also found a fair correlation between miRNAs and the triceps skinfold. In contrast, we did not observe any association between miRNAs and hand-grip, gait speed, or the balance test. 


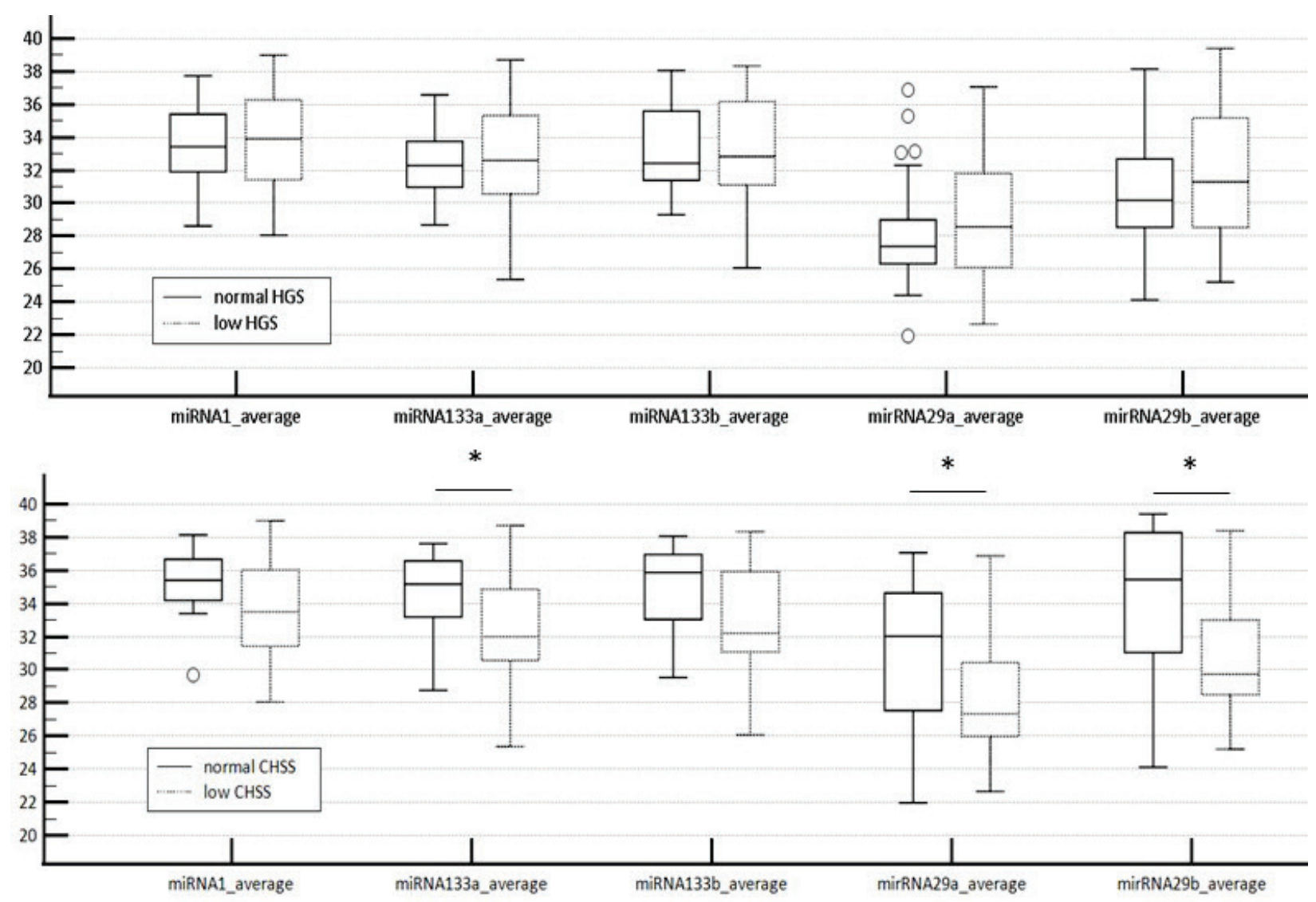

Fig. 1. Comparison of microRNA 1,133a, 133b, 29a and 29b levels according to categorical functional mobility domains. Upper pane: normal (solid square) vs. low handgrip strength (dotted square, men $<30 \mathrm{~kg}$, women $<20 \mathrm{~kg}$ ). Lower pane: normal (solid square) vs. low chair stand speed (dotted square, $<0.5 / \mathrm{s}$ ), Box-whisker plot showing the 25-75th percentile and range, $* \mathrm{p}<0.05$.
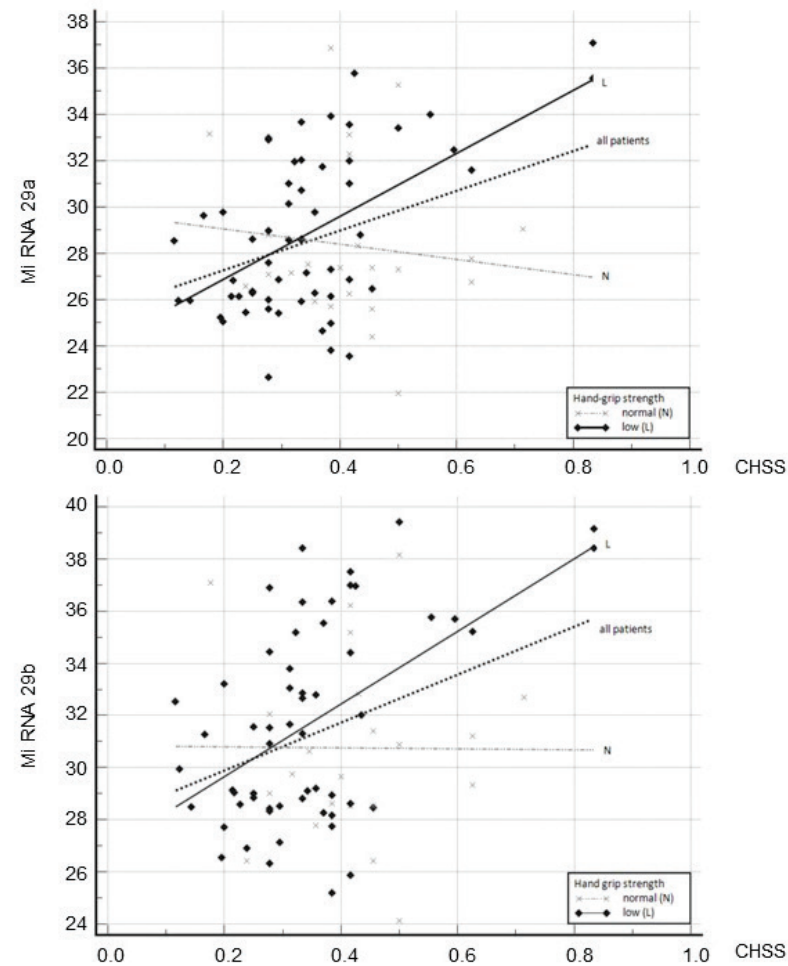

Fig. 2. Correlations between microRNA 29a, miRNA $29 b$ and chair-stand speed (chair stands/s). Left pane: miRNA29a, all patients: $r=0.262, p=0.019$, patients with low handgrip $(L)$ : $r=0.437, p=0.0007$, normal handgrip $(N): r=0.061, p=0.784$. Right pane: miRNA29b, all patients: $r=0.257, p=0.021$, patients with low handgrip $(L): r=0.392, p=0.0026$, normal handgrip $(N)$ : $r=0.0669, p=0.767$.

MiRNA 29 plays a role in the regulation of skeletal muscle homeostasis, is involved in the regulation of myogenesis with important roles in the activation and differentiation of satellite cells and the regulation of insulin signaling (Hilton et al. 2019). Given the available literature to date, we do not find a similar report on the relationship between miRNAs and the CHSS, which makes our report unique. Of interest is the observed correlation of miRNA $29 \mathrm{~b}$ with triceps skinfold. Although it is known that miRNAs are also essential for the formation and function of adipose tissue, their role in regulating the distribution of human fat remains completely unexplored (Hilton et al. 2019). It is known that miRNA 133 and miRNA 1 are also involved in 
Table 3. Comparison of micro-RNA Ct levels by various functional mobility domains

\begin{tabular}{|c|c|c|c|c|c|c|c|}
\hline & \multicolumn{3}{|c|}{ Normal handgrip strength } & \multicolumn{3}{|c|}{ Low handgrip strength } & \multirow[b]{2}{*}{$\mathbf{P}^{\mathbf{a}}$} \\
\hline & n & Median & Average Rank & $\mathbf{n}$ & Median & Average Rank & \\
\hline $\operatorname{miRNA1}$ & 20 & 33.4343 & 32.3 & 49 & 33.918 & 36.102 & 0.4751 \\
\hline $\operatorname{mirRNA29a}$ & 23 & 27.3744 & 38.913 & 57 & 28.572 & 41.1404 & 0.698 \\
\hline $\operatorname{mirRNA29b}$ & 22 & 30.1853 & 37 & 57 & 31.299 & 41.1579 & 0.4704 \\
\hline $\operatorname{miRNA133a}$ & 21 & 32.2967 & 34.7619 & 52 & 32.6082 & 37.9038 & 0.5668 \\
\hline \multirow[t]{3}{*}{$\operatorname{miRNA133b}$} & 22 & 32.4277 & 35.7727 & 52 & 32.8363 & 38.2308 & 0.6531 \\
\hline & \multicolumn{3}{|c|}{ Normal chair-stands speed } & \multicolumn{3}{|c|}{ Low chair-stands speed } & \\
\hline & n & Median & Average Rank & $\mathbf{n}$ & Median & Average Rank & $\mathbf{P}^{\mathbf{a}}$ \\
\hline $\operatorname{miRNA1}$ & 8 & 35.4133 & 45.25 & 61 & 33.5043 & 33.6557 & 0.1243 \\
\hline $\operatorname{mirRNA29a}$ & 12 & 32.033 & 55.5 & 68 & 27.3453 & 37.8529 & 0.0153 \\
\hline $\operatorname{mir} R N A 29 b$ & 12 & 35.452 & 55.8333 & 67 & 29.7397 & 37.1642 & 0.0095 \\
\hline$m i R N A 133 a$ & 9 & 35.1732 & 51.5556 & 64 & 31.9978 & 34.9531 & 0.0279 \\
\hline \multirow[t]{3}{*}{$m i R N A 133 b$} & 8 & 35.8764 & 50.125 & 66 & 32.2045 & 35.9697 & 0.0787 \\
\hline & & \multicolumn{2}{|c|}{ Normal gait speed } & & \multicolumn{2}{|c|}{ Low gait speed } & \\
\hline & n & Median & Average Rank & $\mathbf{n}$ & Median & Average Rank & $\mathbf{P}^{\mathbf{a}}$ \\
\hline $\operatorname{miRNA1}$ & 30 & 33.3077 & 33.4333 & 39 & 33.918 & 36.2051 & 0.5694 \\
\hline $\operatorname{mirRNA29a}$ & 34 & 27.3819 & 39.4118 & 46 & 28.5785 & 41.3043 & 0.7188 \\
\hline $\operatorname{mir} R N A 29 b$ & 33 & 30.6309 & 37.6061 & 46 & 31.279 & 41.7174 & 0.4323 \\
\hline $\operatorname{miRNA133a}$ & 31 & 32.2967 & 36.1935 & 42 & 32.7371 & 37.5952 & 0.7802 \\
\hline \multirow[t]{3}{*}{$\operatorname{miRNA133b}$} & 32 & 32.7057 & 37.25 & 42 & 32.9759 & 37.6905 & 0.9304 \\
\hline & & \multicolumn{2}{|c|}{ Normal balance } & & \multicolumn{2}{|c|}{ Low balance } & \\
\hline & n & Median & Average Rank & n & Median & Average Rank & $\mathbf{P}^{\mathbf{a}}$ \\
\hline $\operatorname{miRNA1}$ & 35 & 33.4028 & 33.5714 & 34 & 33.969 & 36.4706 & 0.5484 \\
\hline $\operatorname{mirRNA29a}$ & 40 & 27.3472 & 39.625 & 40 & 28.4306 & 41.375 & 0.7363 \\
\hline $\operatorname{mirRNA29b}$ & 39 & 29.9535 & 38.7179 & 40 & 31.3909 & 41.25 & 0.6239 \\
\hline $\operatorname{miRNA133a}$ & 38 & 32.9207 & 39.3158 & 35 & 31.8804 & 34.4857 & 0.3312 \\
\hline $\operatorname{miRNA133b}$ & 36 & 33.0095 & 37.25 & 38 & 32.204 & 37.7368 & 0.9225 \\
\hline
\end{tabular}

cut-offs: handgrip males $<30 \mathrm{~kg}$, females $<20 \mathrm{~kg}$, chairstands $<0.5 / \mathrm{s}$, gait speed $<0.8 \mathrm{~m} / \mathrm{s}$, balance $<30 \mathrm{~s}$, ${ }^{\text {a }}$ Mann-Whitney test

Table 4. Accuracy of the miRNAs (Ct) in the prediction of low chair-stands speed $(<0.5 / \mathrm{s})$ among hospitalized patients

\begin{tabular}{|c|c|c|c|c|c|c|}
\hline & \multicolumn{6}{|c|}{ All patients, $n=80$} \\
\hline & AUROC & $95 \%$ CI & $\mathbf{p}$ & cut-off & SEN (\%) & SPE (\%) \\
\hline miRNA $29 a$ & 0.721 & $0.54-0.90$ & 0.02 & $\leq 31$ & 79 & 58 \\
\hline $\operatorname{miRNA} 29 b$ & 0.736 & $0.56-0.91$ & 0.01 & $\leq 35.2$ & 85 & 58 \\
\hline miRNA $133 a$ & 0.727 & $0.53-0.92$ & 0.02 & $\leq 32.6$ & 59 & 89 \\
\hline miRNA $133 b$ & 0.691 & $0.48-0.90$ & 0.07 & $\leq 32.8$ & 56 & 87.5 \\
\hline \multirow[t]{3}{*}{ miRNA 1} & 0.668 & $0.46-0.88$ & 0.11 & $\leq 34.6$ & 67.2 & 75 \\
\hline & \multicolumn{6}{|c|}{ Low hand-grip strength, $n=57$} \\
\hline & AUROC & $95 \%$ CI & $\mathbf{p}$ & cut-off & SEN (\%) & SPE (\%) \\
\hline $\operatorname{miRNA} 29 a$ & 0.928 & $0.83-0.98$ & $<0.001$ & $\leq 31$ & 80.4 & 100 \\
\hline miRNA $29 b$ & 0.928 & $0.83-0.98$ & $<0.001$ & $\leq 35.2$ & 84.3 & 100 \\
\hline miRNA $133 a$ & 0.88 & $0.76-0.95$ & $<0.001$ & $\leq 34.4$ & 71 & 100 \\
\hline miRNA $133 b$ & 0.87 & $0.75-0.95$ & $<0.001$ & $\leq 36.3$ & 80 & 100 \\
\hline miRNA 1 & 0.761 & $0.45-1.0$ & 0.1 & $\leq 36.6$ & 87 & 66.7 \\
\hline
\end{tabular}


skeletal muscle proliferation and differentiation (Chen et al. 2006).

To date, several studies have been performed in humans to explore changes in serum miRNAs while examining the relationship with functional mobility domains (Yanai et al. 2020). The study (Iannone et al. 2020) of 218 individuals from retirement homes (79 men, 139 women) older than 65 years, half of whom were diagnosed as sarcopenic (based on EWGSOP2 criteria), found lower plasma levels of 133b miRNA in individuals with sarcopenia. Lower levels of miRNA 133b and miRNA 206 significantly correlated with poor nutritional status, a positive correlation was observed between plasma levels of miRNA $133 \mathrm{~b}$ and serum albumin and iron. The cross-sectional study (Murabito et al. 2017) examined the relationship of muscle strength measured by handgrip on 299 types of plasma miRNA in 5668 community-living individuals (2616 males, 3052 females, mean age 55.7) from the Framingham Heart Study and Gen 3 studies. Through linear mixed-effects regression modeling found that almost all miRNAs examined had increased miRNA expression associated with increased handgrip strength.

The strongest relationship was observed for miRNA 126-3p, miRNA 30a-5p and miRNA 30d-5p, including miRNA $29 \mathrm{~b}-2-5 \mathrm{p}$ among the top 15 . The study (Ipson et al. 2018) focused on the identification of mRNA isolated from the plasma exosome of 14 community-living robust ( 5 males, 2 females) and frail (Fried frailty phenotype, 7 males) elderly individuals and compared it with samples from 7 healthy university students. Pairwise comparison between groups young vs. frail and robust vs. frail identified eight miRNAs that were differentially expressed and thus unique in frail individuals: miRNA $10 \mathrm{a}-3 \mathrm{p}$, miRNA 92a-3p, miRNA 185-3p, miRNA 194-5p, miRNA 326, miRNA 532-55, miRNA 576-5p and miRNA 760. Among the miRNAs we have examined: miRNA 1, miRNA 133a-1, -2 , miRNA 29a-3p, miRNA 29b 2-5p, $-3 p$, the association was not demonstrated. Another study (He et al. 2020) compared plasma miRNA samples from 93 elderly individuals with sarcopenia and 93 individuals without sarcopenia diagnosed according to the Asian Working Group of Sarcopenia. In individuals with sarcopenia, lower levels of miRNA $208 \mathrm{~b}$ and miRNA 155 were found and they significantly correlated with handgrip strength in women and miRNA 208b, miRNA 499, miRNA 222 significantly correlated with the skeletal muscle mass. However, for miRNA 1, miRNA 133a,
miRNA 133b, significant differences were not observed (He et al. 2020). Similarly, the study of Liu et al. with 77 hospitalized patients (41 men, 36 women) aged 66 to 92 years, of whom 18 were evaluated as sarcopenic, did not reveal significant differences in miRNA 133a. In contrast, they found that levels of miRNA 486 and miRNA 146a were lower in sarcopenic individuals, where they observed an association with skeletal muscle index (SMI) and a correlation with handgrip strength in miRNA 146a (Liu et al. 2021).

Since our study did not evaluate patients for sarcopenia, and our RNA panel was narrower compared to previous studies, we consider the results as complementary. Evaluating patients for sarcopenia according to the current consensus is not feasible in all hospitalized patients. However, measuring functional mobility domains appears easier and provides a clinically relevant argument for decision making. While CHSS is one of the two screening tests for sarcopenia according to the recent consensus (Cruz-Jentoft et al. 2019), it provides a piece of important information on the antigravity domain, which is highly relevant to the prospects of patients' recovery. Although miRNAs with CHSS have not been studied previously, we confirmed that lower functional status reflected in the lower antigravity domain was directly related to reduced levels of several miRNAs. Our study also confirmed that the potential for the use of miRNA 1 , the major musclespecific miRNA, as a biomarker seems to be low (He et al. 2020, Iannone et al. 2020, Ipson et al. 2018). Future studies are needed on the role of selected miRNAs as biomarkers of frailty/sarcopenia focusing on their predictive value for distinct objectively evaluated conditions (abnormal HGS, CHSS, subcutaneous fat) and exploring their impact on relevant clinical endpoints such as length of hospital stay, newly acquired disability or prognosis.

The main strength of our study is the focus on the objective measurement of the selected physical functional domains. Also, the population of hospitalized elderly patients has not received much attention in previous studies with miRNAs, but it represents the most vulnerable population being affected by the impaired functional status and would most benefit from early intervention. Our study has several limitations. Since we found only a single domain being associated with miRNAs, we did not evaluate frailty assessment tools derived from other functional domains such as short performance physical battery test or liver frailty index. 
We did not evaluate patients for sarcopenia according to the recent consensus (Cruz-Jentoft et al. 2019), since not all patients underwent a procedure enabling evaluation of muscle mass. The pre-test probability of low chair stand speed was high in our patients, so the predictive potential of miRNA in this population could have overestimated the true value. Therefore, our results suggesting the high predictive value of miRNA for the impaired antigravitational domain in patients with suspected sarcopenia should be interpreted with caution. However, our finding that miRNAs perform better in patients with low handgrip strength should set the stage for further research on well-balanced and stratified cohorts.

In conclusion, we explored the association of selected miRNAs with physical function domains in hospitalized elderly patients. From all the functional domains, the only chair stands speed correlated with the selected miRNAs. The observed association was significant but relatively weak. However, in patients with low hand-grip strength who are classified according to the EWGSOP2 consensus as those with suspected sarcopenia, the association between miRNA and CHSS was much stronger. MiRNA29a, miRNA 29b, miRNA $133 \mathrm{a}$ and miRNA $133 \mathrm{~b}$ could therefore have potential as biomarkers for identifying patients with some aspects of impaired functional status, in this case, an impaired antigravitational domain in patients with suspected sarcopenia. We also found a fair correlation between miRNAs and the triceps skinfold. In contrast, we did not observe any association between miRNA and handgrip, gait speed, or the balance test. Further studies are needed in more refined cohorts, more targeted panels of miRNA, and relevant clinical endpoints.

\section{Conflict of Interest}

There is no conflict of interest.

\section{References}

BROWN DM, GOLJANEK-WHYSALL K: microRNAs: Modulators of the underlying pathophysiology of sarcopenia? Ageing Res Rev 24: 263-273, 2015. https://doi.org/10.1016/j.arr.2015.08.007

CHEN JF, MANDEL EM, THOMSON JM, WU Q, CALLIS TE, HAMMOND SM, CONLON FL, WANG DZ: The role of microRNA-1 and microRNA-133 in skeletal muscle proliferation and differentiation. Nat Gen 38: 228-233, 2006. https://doi.org/10.1038/ng1725

CHEN X, MAO G, LENG SX: Frailty syndrome: an overview. Clin Interv Aging 9: 433-441, 2014. https://doi.org/10.2147/CIA.S45300

COLLARD RM, BOTER H, SCHOEVERS RA, OUDE VOSHAAR RC: Prevalence of frailty in community-dwelling older persons: a systematic review. J Am Geriatr Soc 60: 1487-1492, 2012. https://doi.org/10.1111/j.15325415.2012.04054.x

CRUZ-JENTOFT AJ, BAHAT G, BAUER J, BOIRIE Y, BRUYERE O, CEDERHOLM T, COOPER C, LANDI F, ROLLAND Y, SAYER AA, SCHNEIDER SM, SIEBER CC, TOPINKOVA E, VANDEWOUDE M, VISSER M, ZAMBONI M: Sarcopenia: revised European consensus on definition and diagnosis. Age Ageing 48: 16-31, 2019. https://doi.org/10.1093/ageing/afy169

CUNHA AIL, VERONESE N, DE MELO BORGES S, RICCI NA: Frailty as a predictor of adverse outcomes in hospitalized older adults: A systematic review and meta-analysis. Ageing Res Rev 56: 100960, 2019. https://doi.org/10.1016/j.arr.2019.100960

DELONG ER, DELONG DM, CLARKE-PEARSON DL: Comparing the areas under two or more correlated receiver operating characteristic curves: a nonparametric approach. Biometrics 44: 837-845, 1988.

DENT E, MORLEY JE, CRUZ-JENTOFT AJ, WOODHOUSE L, RODRÍGUEZ-MAÑAS L, FRIED LP, WOO J, APRAHAMIAN I, SANFORD A, LUNDY J, LANDI F, BEILBY J, MARTIN FC, BAUER JM, FERRUCCI L, MERCHANT RA, DONG B, ARAI H, HOOGENDIJK EO, WON CW, ABBATECOLA A, CEDERHOLM T, STRANDBERG T, GUTIÉRREZ ROBLEDO LM, FLICKER L, BHASIN S, AUBERTINLEHEUDRE M, BISCHOFF-FERRARI HA., GURALNIK JM, MUSCEDERE J, PAHOR M, RUIZ J, NEGM AM, REGINSTER JY, WATERS DL, VELLAS B: Physical Frailty: ICFSR International Clinical Practice Guidelines for Identification and Management. J Nutr Health Aging 23: 771-787, 2019. https://doi.org/10.1007/s12603-019-1273-z 
DLOUHÁ D, HUBÁČEK JA: Regulatory RNAs and cardiovascular disease - with a special focus on circulating microRNAs. Physiol Res 66: S21-S38, 2017. https://doi.org/10.33549/physiolres.933588

GAŽOVÁ A, SAMÁKOVÁ A, LACZO E, HAMAR D, POLÁKOVIČOVÁ M, JURIKOVÁ M, KYSELOVIČ J: Clinical utility of miRNA-1, miRNA-29g and miRNA-133s plasma levels in prostate cancer patients with high-intensity training after androgen-deprivation therapy. Physiol Res 68: S139-S147, 2019. https://doi.org/10.33549/physiolres. 934298

GINGRICH A, VOLKERT D, KIESSWETTER E, THOMANEK M, BACH S, SIEBER CC, ZOPF Y: Prevalence and overlap of sarcopenia, frailty, cachexia and malnutrition in older medical inpatients. BMC Geriatrics 19: 120, 2019. https://doi.org/10.1186/s12877-019-1115-1

GOLJANEK-WHYSALL K, IWANEJKO LA, VASILAKI A, PEKOVIC-VAUGHAN V, MCDONAGH B: Ageing in relation to skeletal muscle dysfunction: redox homoeostasis to regulation of gene expression. Mam Genome 27: 341-357, 2016. https://doi.org/10.1007/s00335-016-9643-x

HE N, ZHANG YL, ZHANG Y, FENG B, ZHENG Z, WANG D, ZHANG S, GUO Q, YE H: Circulating MicroRNAs in plasma decrease in response to sarcopenia in the elderly. Front Genet 11: 167, 2020. https://doi.org/10.3389/fgene.2020.00167.

HILTON C, NEVILLE MJ, WITTEMANS LBL, TODORCEVIC M, PINNICK KE, PULIT SL, LUAN J, KULYTÉ A, DAHLMAN I, WAREHAM NJ, LOTTA LA, ARNER P, LINDGREN CM, LANGENBERG C, KARPE F: MicroRNA-196a links human body fat distribution to adipose tissue extracellular matrix composition. EBioMedicine 44: 467-475, 2019. https://doi.org/10.1016/j.ebiom.2019.05.047

IANNONE F, MONTESANTO A, CIONE E, CROCCO P, CAROLEO MC, DATO S, ROSE G, PASSARINO G: Expression patterns of muscle-specific miR-133b and miR-206 correlate with nutritional status and sarcopenia. Nutrients 12: 297, 2020. https://doi.org/10.3390/nu12020297

IPSON BR, FLETCHER MB, ESPINOZA SE, FISHER AL: Identifying exosome-derived MicroRNAs as candidate biomarkers of frailty. J Frailty Aging 7: 100-103, 2018. https://doi.org/10.14283/jfa.2017.45

LIU HC, HAN DS, HSU CC, WANG JS: Circulating MicroRNA-486 and MicroRNA-146a serve as potential biomarkers of sarcopenia in the older adults. BMC Geriatrics 21: 86, 2021. https://doi.org/10.1186/s12877$\underline{021-02040-0}$

MURABITO JM, RONG J, LUNETTA KL, HUAN T, LIN H, ZHAO Q, FREEDMAN JE, TANRIVERDI K, LEVY D, LARSON MG: Cross-sectional relations of whole-blood miRNA expression levels and hand grip strength in a community sample. Aging Cell 16: 888-894, 2017. https://doi.org/10.1111/acel.12622

NIE M, DENG ZL, LIU J, WANG DZ: Noncoding RNAs, emerging regulators of skeletal muscle development and diseases. BioMed Res Int: 676575, 2015. https://doi.org/10.1155/2015/676575

O'CAOIMH R, GALLUZZO L, RODRÍGUEZ-LASO Á, VAN DER HEYDEN J, RANHOFF AH, LAMPRINI-KOULA M, CIUTAN M, LÓPEZ-SAMANIEGO L, CARCAILlON-BENTATA L, KENNELLY S, LIEW A: Prevalence of frailty at population level in European ADVANTAGE Joint Action Member States: a systematic review and meta-analysis. Annali Dell'Istituto Superiore Di Sanita 54: 226-238, 2018.

OLIVEIRA JS, PINHEIRO MB, FAIRHALL N, WALSH S, CHESTERFIELD FRANKS T, KWOK W, BAUMAN A, SHERRINGTON C: Evidence on physical activity and the prevention of frailty and sarcopenia among older people: a systematic review to inform the world health organization physical activity guidelines. J Phys Activity Health 17: 1247-1258, 2020. https://doi.org/10.1123/jpah.2020-0323

PAPADOPOULOU SK: Sarcopenia: a contemporary health problem among older adult populations. Nutrients 12: 1293, 2020. https://doi.org/10.3390/nu12051293

PICCA A, CALVANI R, CESARI M, LANDI F, BERNABEI R, COELHO-JÚNIOR HJ, MARZETTI E: Biomarkers of physical frailty and sarcopenia: coming up to the place? Int $\mathrm{J}$ Mol Sci 21: 5635, 2020. https://doi.org/10.3390/ijms21165635

SKLADANÝ L, KASSOVÁ S, ŠVÁČ J: Frailty syndrome in internal medicine (Article in Slovak). Intern med 18: 283-286, 2018.

VRBOVÁ P, KOLLER T, PAYER J: Sarcopenia in internal medicine. Via Practica 16: 58-60, 2019. 
WORLD HEALTH ORGANIZATION: WHO Clinical Consortium on Healthy Ageing. In: Topic focus: frailty and intrinsic capacity. Araujo de Carvalho I, Beard J, Thiyagarajan JA, Sumi Y(Eds.), WHO, Geneva, 2017, pp 3-11.

YANAI K, KANEKO S, ISHII H, AOMATSU A, ITO K, HIRAI K, OOKAWARA S, ISHIBASHI K, MORISHITA Y: MicroRNAs in sarcopenia: a systematic review. Front Med 7: $180,2020$. https://doi.org/10.3389/fmed.2020.00180 